\title{
La noción de equipartición de fracción y sus herramientas de verificación en un contexto musical
}

\author{
Gerardo Elías Sepúlveda Restrepo ${ }^{1}$ \\ ORCID: 0000-0003-0149-1668 \\ Marco Antonio Ayala Chauvin ${ }^{2}$ \\ ORCID: 0000-0002-0084-6773 \\ Luis Alexander Conde Solano ${ }^{3}$ \\ ORCID: 0000-0002-2118-4465
}

\section{Resumen}

El objetivo de esta investigación consiste en analizar la construcción de la noción de equipartición en estudiantes de primaria, a través de objetos musicales. Este interés surgió al observar que los métodos utilizados en la actualidad para la enseñanza de las fracciones no ofrecen un mecanismo de comprobación de la existencia o no de la equidad de las partes. Por lo tanto, en este estudio se pretende proveer a los estudiantes de diversas herramientas para identificar las consecuencias acústicas que surgen del incumplimiento de la equipartición. Las mismas pueden ser representadas de forma visual, corporales y auditiva. Esta investigación de tipo cualitativo y desarrollo curricular se realizó con estudiantes de $4^{\circ}$ y $5^{\circ}$ grado de educación primaria en un contexto rural, ubicada al occidente de Antioquia, Colombia. Dentro de los hallazgos de la investigación, se considera que los estudiantes inmersos en un mundo interdisciplinar real adquieren herramientas físicas y simbólicas para determinar la existencia o no de una equipartición. Es así como los escenarios diferentes a los tradicionales, dotados de experiencias y representaciones, logran contribuir a la construcción de la noción de equipartición en los estudiantes.

\section{Palabras clave}

Equipartición - Objetos musicales - Fracción - Representaciones.

\footnotetext{
1- Secretaría de Educación de Antioquia, Colombia. Contacto: illecebris@hotmail.com.

2- Universidad Técnica Particular de Loja (UTPL), Loja, Ecuador. Contacto: maayala5@utpl.edu.ec.

3- Universidad de Medellín, Colombia. Contacto: Iconde@udem.edu.co.
}

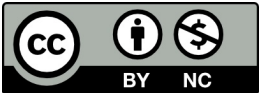




\section{The notion of equipartition of fraction and its verification tools in a musical context}

\section{Abstract}

The objective of this research is to analyze the construction of the concept of equipartition in elementary students, through musical objects. This interest arose upon observing that the methods currently used to teach fractions do not offer a mechanism for checking the existence of the equality of the parties. Therefore, this study aims to provide students with various tools to identify the acoustic consequences that arise from non-compliance with equipartition. They can be represented in a visual, bodily, and auditory way. This qualitative research with curricular development was conducted among 4th and 5 th graders of elementary school in a rural context. The findings of the research include the fact that students, by immersing themselves in a real interdisciplinary world, acquire physical and symbolic tools to determine the existence or not of a equipartition. This is how scenarios other than the traditional ones, endowed with experiences and representations, contribute to the construction of the notion of equipartition in students.

\section{Keywords}

Equipartition - Musical objects - Fraction - Representations.

\section{Introducción}

Desde las dinámicas de enseñanza y aprendizaje, las matemáticas causan sentimientos encontrados entre los estudiantes. Esto establece un reto para los maestros, al demandar que las estrategias didácticas utilizadas en la enseñanza de esta área estén dotadas de elementos que generen interés por el estudio de las matemáticas. Para este fin, se entiende que la música representa un contexto potencial desde su proximidad natural a las personas donde se podría promover métodos de comunicación, construcción de valores, generar emociones, introducir nuevos lenguajes, saberes, formas de hacer y comprender el mundo, todo desde lo científico, cultural y tecnológico (PÉREZ, 2009).

A pesar de la importancia de la música en la escuela, como eje transversal o disciplina, la preocupación por realizar aportes al estudio de la diada músicamatemáticas en el campo de la enseñanza se hace imperante si se observa la estructura de los currículos de las instituciones de educación pública colombianas. En ellos, inevitablemente, se les da amplio interés a las matemáticas, transmitidas desde métodos rígidos, con una visión atomista de contenidos y, en ocasiones, como instrumento de poder. Mientras que la música tiene un lugar recreativo, al servicio de la clase de artística y con poca relevancia. 
El estudio de los vínculos entre las matemáticas y la música ha despertado interés desde Confucio (551-479 a. C), Pitágoras (580-495 a. C) y sus discípulos, la cultura griega en general con el estudio del quadrivium (aritmética, música, geometría y astronomía), San Agustín de Hipona (354-430 d. C.), entre otros, sentaron las bases para la estructuración del lenguaje musical, la composición, la construcción de instrumentos, en esencia, el establecimiento de la música como arte y ciencia, estrechamente ligada a las matemáticas.

En una mirada contemporánea de este fenómeno de estudio, algunos autores como Tiburcio (2002), Peralta (2003), Naik y Subramaniam (2008), Liern (2011), Conde (2009, 2013), Silva (2009), Conde, Parada y Liern (2016), entre otros, han manifestado que existen posibilidades didácticas de enseñar matemáticas a través de la música, especialmente las fracciones, generando nuevos medios de interpretación y creación de nociones alrededor del tema. Aprovechando estos hallazgos, aquí se procura ofrecer un contexto diferente a los tradicionales, en el cual estudiantes y maestros tendrán elementos para discriminar la existencia o no de la equidad de las partes en la enseñanza y aprendizaje de las fracciones.

\section{Conexiones entre las fracciones y el tiempo musical}

La música como el arte de organizar sensible y lógicamente una combinación coherente de sonidos y silencios requiere de fundamentos de la física y de la matemática para explicar y teorizar aspectos como ondas de sonido, medios de propagación y cualidades del sonido, entre otras. Para Fenlon (2000) medir con exactitud la música, leída o interpretada, es posible porque existe sólo en el tiempo, es decir, trascurre en el tiempo y en él se articula. La estructura matemática permite hacer discreto el tiempo en términos fraccionarios, posibilitando el reconocimiento de la duración de una figura y nota musical ubicada en un pentagrama. En este estudio se centra la atención en los sonidos que pueden escuchar las personas, sin detenerse a estudiar a profundidad la esencia vibratoria de los mismos (SCHAEFFER, 1988).

\section{La medida del tiempo}

La construcción de la noción de tiempo es una de las más complejas en el aprendizaje de los estudiantes entre 8 y 12 años de edad. En Piaget (1978) se habla sobre la dificultad con la que los niños se enfrentan para comprender la noción de edad, sucesión, duración, anterioridad y posterioridad. La mente del niño requiere de la formación de estructuras organizacionales que le permitan aprehender estas diferentes nociones y, en consecuencia, es necesario crear situaciones de aprendizaje en las que los niños tengan experiencias personales conducentes al entendimiento de las nociones del tiempo.

Piaget (1978), indicó que la ordenación de una secuencia temporal demanda del proceso de reversibilidad que no se alcanza hasta que se inicia el periodo de las operaciones concretas. Es conveniente que antes de que el niño adquiera la noción de tiempo realice actividades que le permitan distinguir en una serie de sucesos el orden temporal y que comprenda que entre dos sucesos existe un intervalo de tiempo que se puede valorar. 
Por otra parte, según Piaget (1965) no hay una intuición primaria de la duración para el niño, sino que ésta se evalúa a partir de la relación que establece entre una acción y la velocidad con la que se realiza. Al principio, la velocidad es una intuición: el niño intuye que alcanza un objeto, o que lo sobrepasa. Después, a medida que se va produciendo la evolución operatoria, el niño concibe la velocidad como la relación entre el espacio recorrido y el tiempo empleado. Es decir, la noción de tiempo se construye a partir de las nociones espaciales y de experimentaciones de distintas velocidades.

\section{Las fracciones en el contexto escolar}

La enseñanza y el aprendizaje de las fracciones representan una temática esencial en el currículo escolar. Las dificultades que se presentan durante la enseñanza de las fracciones se refleja en un alto porcentaje de estudiantes que fracasan en aprender el concepto de fracción. Al respecto, Kieren $(1976,1988)$ y Socas (1997) han mostrado que los alumnos tratan los números racionales de la misma manera que los naturales. Ellos mencionan que, por ejemplo, los estudiantes tienen la idea de que la multiplicación hace más grande una cantidad $y$, al ver que los términos de una fracción que se multiplica por cierta cantidad de manera independiente se vuelven más grandes, confirman su suposición, de lo cual se entiende que no ven todavía a la fracción como un sólo número. En aspecto operativo, Prediger y Schink (2009) señalan que un significado importante de la multiplicación de fracciones es la parte de parte de un conjunto (part-of-part-model), porque $4 / 5 \times 2 / 3$ se interpreta como 4/5 de 2/3. La comprensión de los estudiantes de este modelo puede ser limitada por la dificultad de identificar el todo y la parte de ese todo, el cual a menudo se representa como conjuntos de elementos. Naik y Subramaniam (2008) afirman que en situaciones en las que el conteo se utiliza para llegar a la cardinalidad de un grupo concreto, el tamaño de cada unidad puede ser ignorado. En la investigación acá exhibida, las acciones multiplicativas, según Conde (2013), están inmersas en la fracción como operador y las iteraciones de los mismos. Aquí se identifican tres situaciones sobre el uso de operadores: i) un operador (1/2 de...) en la construcción de figuras y silencios musicales; ii) operadores que generan subunidades, por ejemplo, un cuarto de una figura redonda y iii) operadores en la estructura fraccionaria de los compases.

En cuanto a la equipartición, Cortina, Zúñiga y Visnovska (2013) plantean la conjetura de que su uso en la enseñanza inicial de las fracciones constituye un obstáculo didáctico. Allí, los autores presentan dos propuestas de enseñanza de las fracciones para evitar el uso de la equipartición, ancladas en la idea de que la noción de fracción surge de la conmensuración y también de su concepción como comparador. Al respecto, se concuerda que parte de la problemática de la enseñanza de las fracciones radica en la dimensión didáctica. Sin embargo y en contraste con estos autores, acá se expone la importancia de construir la noción de equipartición en el estudio de las fracciones al inicio de la matemática escolar. Dicha convicción se fundamenta en proporcionar los medios para que los estudiantes encuentren los significados y las necesidades de aplicar una equipartición en contextos donde la medida y el tamaño de la unidad son indispensables. Por ejemplo, las figuras negras se consideran como unidad que representan equiparticiones de tiempo 
de la figura redonda. En caso contrario ocurre un fenómeno físico que no se ajusta a la métrica musical. De esta manera el estudiante comprende lo importante de la equipartición en las consecuencias acústicas de no serlo.

\section{Marco conceptual}

Para el interés de este trabajo damos relevancia a las conexiones entre las matemáticas y la música, a partir de las representaciones semióticas -visuales desde la perspectiva de D`Amore (2009); auditiva y corporales basadas en Conde (2013)-, como puente dialéctico entre dichas disciplinas. Desde esta perspectiva, se estable un marco conceptual que sirve de soporte para el desarrollo de este estudio, centrado en una característica común: los signos de la música pueden ser representaciones de fenómenos sonoros susceptibles de ser descritos a través de las matemáticas (CONDE, 2013).

En esta investigación, los signos (musicales y matemáticos) son tomados como objetos reales, imaginarios o intuitivos por medio de los cuales algo adquiere significado para alguien. La caracterización del signo permite comprender objetos involucrados en las relaciones cognitivas entre las matemáticas y la música (CONDE, 2013). Así mismo, los objetos a los que hacemos referencia pueden ser caracterizados como híbridos compuestos por una naturaleza matemática y otra musical. De tal forma, se conciben a los objetos matemático-musicales como emergentes de las prácticas humanas que los construyen, caracterizan y los ubican dentro de un sistema. En el sistema temporal-musical, se podría tratar el tiempo de duración de un sonido como un objeto matemático-musical por su naturaleza sonora y su medida con estructura fraccionaria (CONDE, 2013).

\section{Representación de los objetos matemático-musicales}

El tratamiento de objetos matemático-musicales demanda formas de representación de dichos objetos. Su caracterización, desde este estudio, se vale de un tratamiento visual, sonoro y corporal que se configura en un marco conceptual inspirado en diferentes autores. De aquí, la aproximación a los objetos matemático-musicales involucran: la representación visual, la representación auditiva y la representación corporal.

En este sentido, promover experiencias auditivas en los estudiantes favorece la creación de representaciones mentales que permiten discriminar, comprender y relacionar estímulos auditivos musicales con ciertos objetos matemáticos, como en el caso de la noción de equipartición en el estudio de las fracciones. Los constantes refinamientos de las formas de representar visual, auditiva y gestual de los objetos matemático-musicales proporcionan al estudiante herramientas de comprobación y argumentación para dar cuenta, por sus propios medios, sobre la construcción y el significado de un concepto estudiado. Estos diferentes acercamientos y representaciones que el estudiante tiene con los objetos matemático-musicales caracterizan los procesos que hacen concretos dichos objetos (WILENSKY, 1991). 


\section{Representación visual}

Entendemos por representaciones visuales aquellas representaciones pictóricas como diagramas, gráficos, modelos geométricos, animaciones dinámicas virtuales, entre otras, como método para comunicar matemáticas y música. Por ejemplo, se podría establecer una comparación entre dos representaciones bidimensionales. Por el lado de la música el pentagrama y por la matemática el plano cartesiano. En el pentagrama los movimientos en el espacio son representados visualmente por la ubicación de las figuras musicales que corresponde a las frecuencias de los sonidos disponiendo los sonidos graves a un movimiento espacial hacia abajo y los sonidos agudos a un movimiento hacia arriba (ZBIKOWSKI, 1997). La representación visual correspondiente al pentagrama se atañe al plano cartesiano donde los movimientos espaciales arriba y abajo se relacionan con el eje vertical correspondiente a las frecuencias de sonidos. El movimiento temporal se puede ubicar en el plano cartesiano en el eje horizontal explícito por el tiempo de duración de sonidos y silencios de cada frecuencia.

En el ámbito de las matemáticas De Guzmán (1996) señala que los matemáticos se valen de procesos simbólicos y diagramas visuales, aún en aquellas actividades matemáticas en las que la abstracción parece llevarnos mucho más lejos de lo perceptible por la vista. Como consecuencia, la visualización aparece así, como algo profundamente natural en la comunicación propia del quehacer matemático. En esta dirección, Arcavi (1999) entiende la visualización como el proceso y el producto de creación, interpretación, empleo y reflexión sobre cuadros, imágenes, diagramas en la mente, en papel o con herramientas tecnológicas. Desde esta investigación se considera que la relación espacio temporal se constituye en un sistema de representación encargado de organizar la duración de los sonidos y silencios en una línea de tiempo de forma simbólica.

\section{Representación auditiva}

A diferencia de la actividad matemática, en la música se responde a la naturaleza de evento sonoro, en la cual la representación visual no es la única forma de comunicación y expresión, ya que un músico puede interpretar una melodía sin conocer dicho sistema de escritura.

La representación auditiva implica el desciframiento (reconocer, discriminar e interpretar) de estímulos auditivos asociándolos a experiencias previas (MCADAMS, 1993). De esta forma, oír con atención es escuchar y escuchar música con atención supone descubrir las diferentes cualidades del sonido, que en su conjunto permiten disfrutar del fenómeno musical. La música está compuesta por cuatro elementos esenciales: la melodía, la armonía, el timbre y el ritmo. El estudio que aquí se presenta se enfoca en un sólo elemento el ritmo por su carácter temporal, su independencia de los otros elementos y por su percepción natural. La proximidad del ritmo es natural para la mayoría de las personas, ya que desde los primeros años de vida se reconocen sonido y patrones rítmicos (SHILLING, 2002). Por ejemplo, una representación auditiva de objetos matemáticomusicales, podría ser que sin tener un contacto visual un niño identifica a su padre por 
medio de sus pisadas, las cuales determinan un patrón rítmico particular. Una de las bondades de esta clase de propuesta es que, para ser implementada en el sistema escolar, no se requiere de conocimientos profundos musicales ni matemáticos por parte de los estudiantes y profesores.

\section{Representación corporal}

Las situaciones y movimientos se dan en un espacio y en un tiempo determinado, es así como a través de las nociones espaciales el niño adquiere las ideas de duración e intervalo. A partir de las múltiples experiencias corporales se forman esquemas que el individuo experimenta de forma recurrente. Para Johnson (1987) algunas de estas experiencias comparten rasgos comunes que se abstraen para dar lugar a los esquemas encarnados. Tanto las experiencias como los rasgos comunes entre ellas tienen un origen corporal, ya que surgen y son consecuencia de las experiencias vividas corporalmente.

Johnson (1987) considera un esquema encarnado como un patrón recurrente de nuestras interacciones perceptuales y programas motores que dan coherencia y estructura a nuestra experiencia. El término patrón alude a la naturaleza abstracta del esquema, que posee una estructura interna determinada. La recurrencia de dichos patrones apela a la necesidad de que existan experiencias repetidas. Dichas experiencias han de ser interactivas porque implican relación con el entorno y han de ser corporales, ya que se experimentan a través de nuestro cuerpo.

Aquí se toman las experiencias corporales rítmicas como casos particulares de las demás experiencias vividas corporalmente. En la ejecución musical el gesto es un elemento inherente que puede ser relacionado corporalmente con el ritmo. Es decir, la experimentación sensorial de fenómenos sonoros permite a los estudiantes reconocer estructuras rítmicas por medio de su actividad corporal.

\section{El tiempo musical y sus equiparticiones}

El desarrollo de la dimensión temporal en la música surge con la polifonía (interpretación de diferentes melodías simultáneamente), que empieza a complejizar la labor de los compositores para encajar varias voces y para escribir música instrumental ya que se carecía de un código establecido. La necesidad de crear representaciones semióticas que expresaran los valores relativos de las notas dentro de una única línea melódica era inevitable. Las representaciones semióticas son aquellas producciones constituidas por el empleo de signos que pertenecen a un sistema de representación (DUVAL, 1998). Una figura geométrica, una figura musical, una fórmula algebraica, un pentagrama, un enunciado en lengua natural, una gráfica; son representaciones semióticas que pertenecen a sistemas semióticos diferentes.

Según Tiburcio (2002) a partir del siglo IX se fue consolidando la necesidad de una notación rítmicamente exacta, como la notación proporcional. Para finales del siglo XIX e inicios del siglo XX, una página de casi cualquier partitura presenta un sistema de signos en el que el ritmo, la altura y la duración de las notas musicales aparecen 
cuantificados con exactitud con respecto a la que la precede; todo ello a su vez con otras clases de instrucción dinámica como la acentuación, la velocidad, la técnica con la que deba interpretarse cada efecto.

La trascendencia de la propiedad que cada figura es la mitad de la anterior y el doble de la siguiente, es utilizada para la construcción de las figuras y silencios musicales (Figura 1) como representaciones semióticas encargadas de medir el tiempo de duración de un sonido o ausencia del mismo. Estas representaciones permiten fijar la música en el tiempo.

Figura 1- Valores de las Figuras y Silencios Musicales (CONDE, 2009, p. 51)

\begin{tabular}{|c|c|c|c|c|c|}
\hline Símbolo & Nombre & Equivalencia & Símbolo & Nombre & Equivalencia \\
\hline & Redonda & 1 & $\square$ & Redonda & 1 \\
\hline & Blanca & 2 & & $\begin{array}{l}\text { Silencio de } \\
\text { Blanca }\end{array}$ & 2 \\
\hline & Negra & 4 & & $\begin{array}{l}\text { Silencio de } \\
\text { Negra }\end{array}$ & 4 \\
\hline & Corchea & 8 & & Corchea & 8 \\
\hline & Semicorchea & 16 & & Semicorchea & 16 \\
\hline $\bar{R}$ & Fusa & 32 & & Fusa & 32 \\
\hline$\overline{\mathrm{E}}$ & Semifusa & & $\mathscr{7}^{\prime}$ & $\begin{array}{l}\text { Silencio de } \\
\text { Semifusa }\end{array}$ & 64 \\
\hline
\end{tabular}

Fuente: Construcción propia.

Para establecer un sistema de medida fue necesario el uso de objetos matemáticos como el objeto de fracción ya que al aplicar el operador matemático que saca la mitad de se construye una sucesión con estructura fraccionaria de la forma $1 / 2^{\mathrm{n}}$, donde $\mathrm{n} \in \mathrm{Z}^{+}$.

\section{Equiparticiones}

En este estudio se procura dar un significado a la equipartición en el contexto musical, utilizando las relaciones estrechas de las fracciones con las figuras, silencios musicales y el compás, partiendo de la necesaria equidad de las partes que los conforman.

Para Kieren (1980) la equipartición es un elemento fundamental en el acercamiento a las fracciones. Sin embargo, Freudenthal (1983) y Cortina, Zuñiga y Visnovska (2013) recomiendan sortear algunos procedimientos que llegarian a 
convertirse en obstáculos didácticos para un aprendizaje maduro del concepto. En este sentido, los planteamientos del presente trabajo no se sustentan en métodos tradicionales de enseñanza que toman como base el ejemplo del pastel, la pizza, la chocolatina, entre otros, entendiendo que estos conducirían a los estudiantes a una idea poco significativa de las fracciones. Según Godino (2004) señala que al parecer las primeras ideas de fracción de los niños son proveídas en un medio tridimensional e impreciso en el desarrollo de la fracción.

La equipartición aquí es tratada desde una perspectiva de medición, que sigue dos principios: el primero consiste en que, a toda figura musical de la misma clase y su silencio corresponde la misma duración; mientras que el segundo se centra en asumir el compás como una composición de equiparticiones. Si alguno de éstos no se cumple, habrá una experiencia sensorial consecuente desde lo visual, corporal y auditivo.

\section{Artefactos mediadores}

Durante las actividades matemáticas mediadas, los estudiantes producen una variedad de signos como palabras, gestos, acciones sobre las herramientas, interacciones y símbolos escritos-orales de cualquier naturaleza. Estos recursos semióticos de manera multimodal son usados tanto por estudiantes como por maestros en los procesos de enseñanza y aprendizaje (ARZARELLO et al., 2009).

Según Vygotsky (1995) los signos, significados, lenguaje y pensamiento, entre otros, son considerados como procesos psicológicos de origen social y como tal, son mediadores semióticos entre la persona y el conocimiento. El conocimiento es algo que se construye por interacciones sociales y mediación de herramientas. En estas interacciones se aprenden formas de entender, explicar y construir el entendimiento de las cosas.

Se considera trascendental en este trabajo la incorporación de la computadora en la creación de experiencias, ya que con esta herramienta se puede ofrecer un abanico de representaciones dinámicas. También se dispone de material concreto que promueve otras experiencias complementarias a las generadas computacionalmente.

\section{Metodología}

Esta es una investigación derivada de una tesis de maestría en Educación Matemática. Es de corte cualitativo que pretende comprender los fenómenos, explorándolos desde la perspectiva de los estudiantes en un ambiente escolar regular, y en relación con su contexto. Una primera fase de la investigación consistió en el diseño y desarrollo curricular que se configuró en una propuesta didáctica. La segunda parte se ubica dentro de una perspectiva cualitativa de análisis, dado que el interés es analizar la manera en que los estudiantes de primaria construyen una noción de equipartición, a través de objetos musicales. En este estudio participaron 17 estudiantes de los grados cuarto y quinto de una institución educativa rural ubicada al occidente de Antioquia, Colombia. 


\section{Diseño de la propuesta de intervención}

La propuesta didáctica fue diseñada para los grados de cuarto y quinto de básica primaria, con posibilidades de adaptación a grados anteriores o posteriores, según los niveles de desempeño de los estudiantes y sus necesidades de formación. Consta de cinco sesiones en las que se establecen objetivos de aprendizaje, se identifican los referentes de calidad educativa del país y se implementan recursos de apoyo transversales a las actividades de aprendizaje.

Los recursos de apoyo fueron elaborados como soporte a las acciones de intervención. El primero de ellos es la guía del docente, la cual presenta la planeación detallada de cada sesión mediante diferentes momentos de la clase; cada actividad fue descrita de acuerdo a su finalidad, en articulación con los demás recursos.

El segundo documento es un cuaderno de trabajo que cumple intensión de favorecer la autonomía para el desarrollo de las actividades y orientación del aprendizaje. Este recurso contiene canciones, ejercicios, esquemas y preguntas generadoras de reflexión, descritas en la guía del docente.

Los autores de este artículo crearon un entorno virtual de tipo multimedial con el propósito de desarrollar representaciones semióticas estáticas y dinámicas (representaciones auditivas y visuales), asimismo simulaciones de objetos matemático-musicales (figuras y silencios musicales-fracciones de tiempo de duración de un sonido) ver Figura 2.

Figura 2- Escena principal del entorno virtual

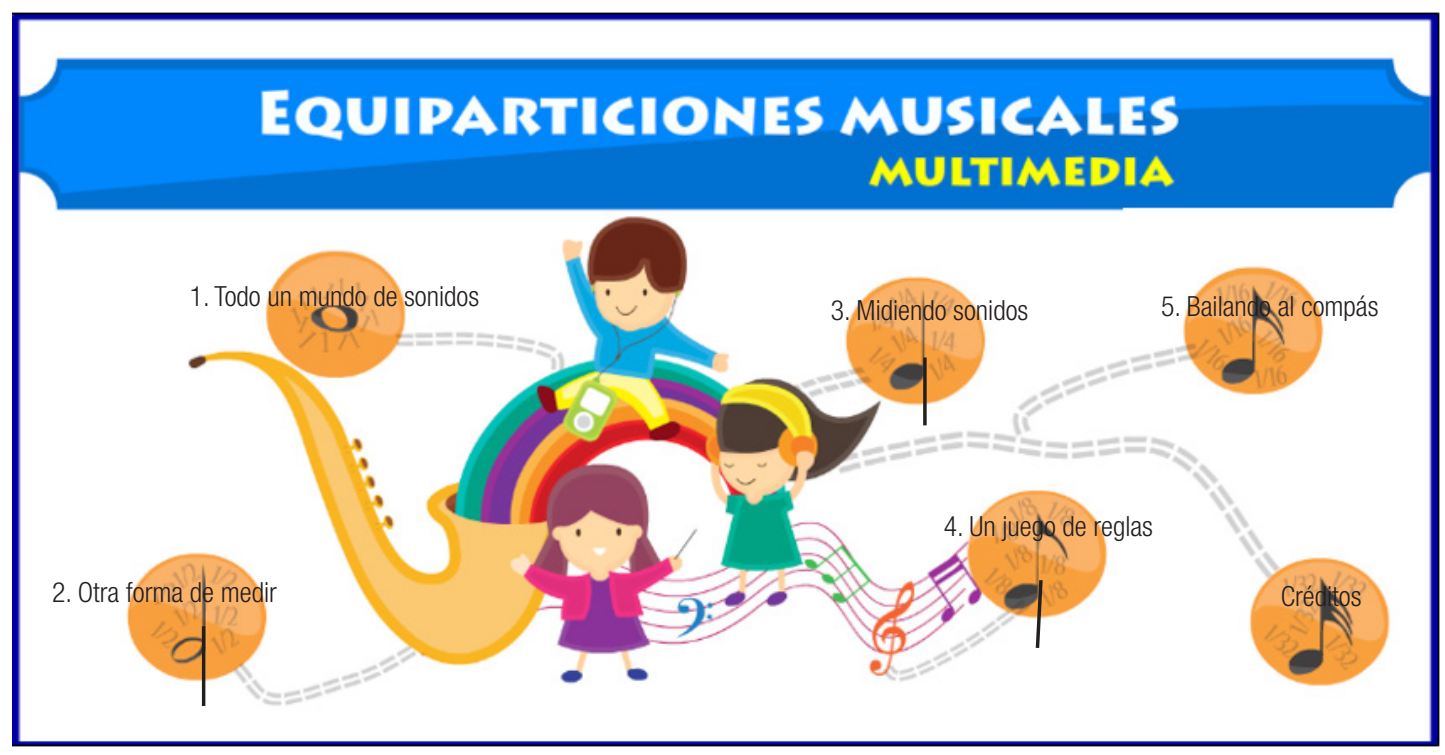

Fuente: Presentación de la multimedia. 
Finalmente, con el fin de ampliar las posibilidades de representación, se diseñó de un material concreto, partiendo de una comparación de la duración de los sonidos con una parte o la totalidad del área de un círculo, tomando la figura completa como la redonda, la mitad de esta como la blanca, un cuarto como la negra y así sucesivamente. Cada grupo de fichas se pintó del mismo color y se construyeron: 1 ficha para la redonda, 2 para la blanca, 4 para la negra, 8 para la corchea, 16 para la semicorchea, 32 para la fusa y 64 para la semifusa. A su vez, se tuvo como criterio que cada ficha equivalente a una figura fuera de igual tamaño que las demás de ese grupo, para así cumplir con el criterio de equipartición (Figura 3).

Figura 3- Ejemplo de guía para elaborar el material manipulativo

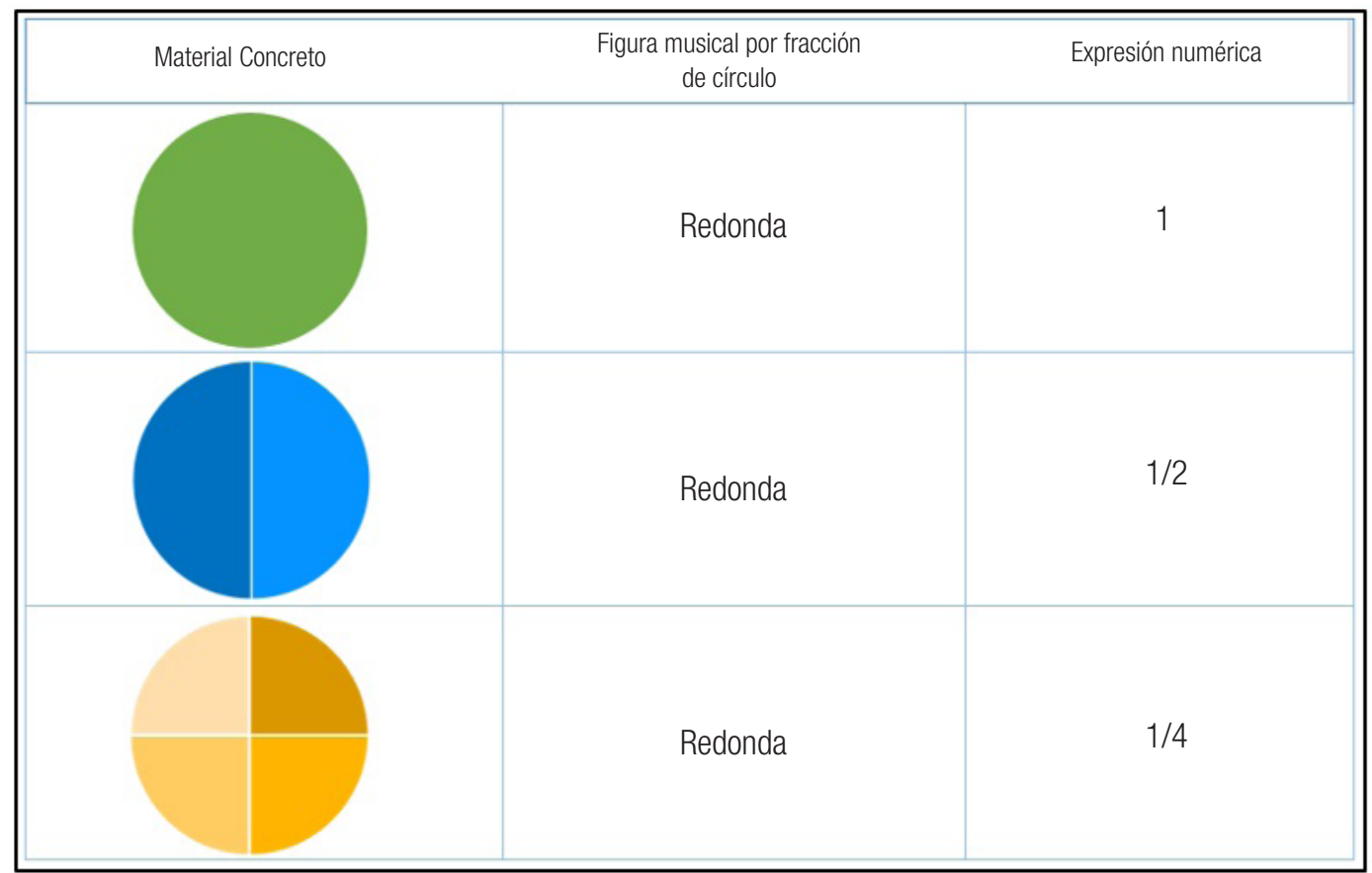

Fuente: Construcción propia.

\section{Trabajo de campo: experiencia de la propuesta didáctica}

En la Tabla 1 se sintetizan las categorias de análisis emergentes de los datos. Para ilustrar las evidencias de cada categoría se exhibieron transcripciones de diálogos, imágenes y episodios de video que paulatinamente señalan cómo se va configurando la construcción de la noción de equipartición en los estudiantes. Los datos presentados que dan cuenta de dicho proceso son tomados de instrumentos como cuadernos de trabajo diligenciados por los estudiantes, videograbaciones de las sesiones y un diario pedagógico. 
Tabla 1- Descripción de categorías de análisis

\begin{tabular}{|c|c|c|}
\hline N. ${ }^{\circ}$ & Categoría & Descripción \\
\hline 1 & $\begin{array}{l}\text { La medida como punto de } \\
\text { encuentro entre las matemáticas y } \\
\text { la música. }\end{array}$ & $\begin{array}{c}\text { El estudiante inicia la adquisición de bases, reconociendo las cualidades del sonido como } \\
\text { objetos musicales que permiten establecer criterios de medición, así como diferentes relaciones } \\
\text { y representaciones matemáticas. }\end{array}$ \\
\hline 2 & $\begin{array}{l}\text { Aproximación inicial a la noción de } \\
\text { equipartición. }\end{array}$ & $\begin{array}{l}\text { Se aborda el planteamiento de que el pulso en sus interacciones con otros objetos musicales, } \\
\text { representa una forma de equipartición. }\end{array}$ \\
\hline 3 & $\begin{array}{l}\text { Sistema de signos para medir el } \\
\text { tiempo. }\end{array}$ & $\begin{array}{l}\text { La equipartición de fracciones es vista desde la identificación del número de pulsos o partes } \\
\text { de estos, que componen cada figura musical. El estudiante hace comparación de magnitudes, } \\
\text { asumiendo la fracción como medida. }\end{array}$ \\
\hline 4 & $\begin{array}{l}\text { Toda figura de la misma clase, tiene } \\
\text { la misma duración. }\end{array}$ & $\begin{array}{l}\text { El incumplimiento de la equipartición en las figuras musicales trae una consecuencia } \\
\text { perceptible, evaluable y susceptible de ser representada desde lo auditivo, gráfico y corporal. }\end{array}$ \\
\hline 5 & $\begin{array}{l}\text { El compás como composición de } \\
\text { equiparticiones. }\end{array}$ & Se estudian las consecuencias de que uno o dos compases no sean equiparticiones entre sí. \\
\hline
\end{tabular}

Fuente: Datos de la investigación.

En los párrafos siguientes se enseñarán en el mismo orden las evidencias de cada una de las categorías descritas en la Tabla 1.

\section{La medida como punto de encuentro entre las matemáticas y la música}

Una de las actividades introductorias consistía en hacer composiciones, en las que se usaran trazos diferenciados para indicar cada cualidad del sonido. Por ejemplo: la altura se expresaba con la ubicación de los gráficos en el espacio, arriba y abajo; el timbre se marcaba diferenciando los colores, la intensidad variaba según la fuerza con que se realizaban las figuras y la duración, con líneas cortas o largas. Además, se les pedía formar parejas y cantar sus creaciones según las reglas descritas. En la Figura 4, se observa un orden de eventos según los trazos de los estudiantes. Básicamente esta idea genera en los estudiantes una noción de línea tiempo que implica una medida, en particular, se enfatizó en los trazos que determinan la duración de los sonidos según las líneas cortas o largas. Al realizar la interpretación acústica de los trazos, se observa en los estudiantes el interés de lograr una articulación de representaciones visuales, auditivas y corporales. Dicho interés puede estar relacionado por la necesidad de comprender los sonidos musicales a través de actividades que nosotros mismos experimentemos.

Figura 4- Composición con cualidades del sonido

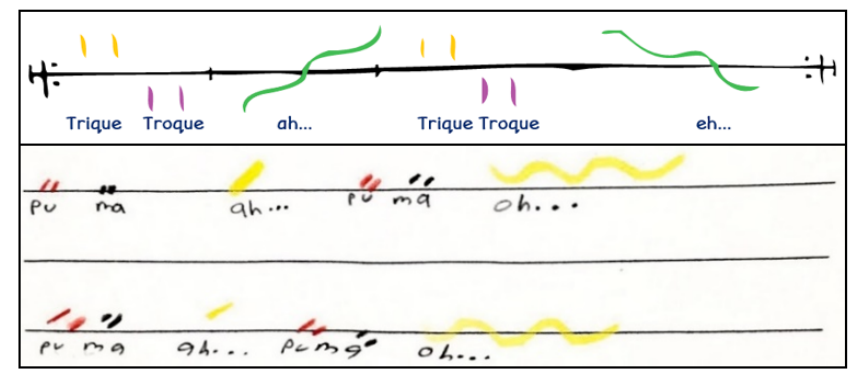

Fuente: Datos de la investigación. 
Las diferentes expresiones de los estudiantes son manifestaciones de las formas individuales de apropiarse de un fenómeno acústico experimentado. Se infiere que ellos relacionan cada sonido con una representación no convencional, como producto del reconocimiento del sonido y cuya imagen mental espacio temporal construida se representa y se ubica dentro de un sistema. Desde esta perspectiva las acciones son inherentes de un proceso perceptivo permeado por la articulación intuitiva de las diferentes representaciones.

\section{Aproximación inicial a la noción de equipartición}

Se realizó una actividad de percepción corporal en la que se les pidió a los estudiantes que formaran parejas y buscaran el pulso de su compañero. Al principio debían reconocer las sensaciones y los detalles percibidos, para luego salir a campo abierto a realizar una actividad física que les generara cansancio y tomar de nuevo las impresiones. Durante el ejercicio, debían dar respuesta a varias preguntas organizadas como se muestra en la Figura 5.

Figura 5- Experimentación de medida del pulso cardíaco

\begin{tabular}{|c|c|c|}
\hline Pregunta & $\begin{array}{c}\text { Resspuesta } \\
\text { (Lo que sientes, descripclones..) }\end{array}$ & $\begin{array}{c}\text { Razones } \\
\text { (Por qué diste la respuesta anterior) }\end{array}$ \\
\hline ¿Qué sientes? & $\begin{array}{l}\text { Que algo brinca como } \\
\text { unos latidos }\end{array}$ & $\begin{array}{l}\text { Porque esta circulando } 19 \\
\text { sangre por las venas } \\
\text { a mosotros las tocamos }\end{array}$ \\
\hline $\begin{array}{l}\text { ¿Cómo podría } \\
\text { describirse la } \\
\text { distancia entre un } \\
\text { golpe y otro? }\end{array}$ & $\begin{array}{l}\text { aue la destancia es } \\
\text { ra mistina y no se va } \\
\text { a sentir mas rapido } \\
\text { hasta que estes cansado }\end{array}$ & $\begin{array}{l}\text { porque la persona no esta } \\
\text { cansada y esta en } \\
\text { calma }\end{array}$ \\
\hline $\begin{array}{l}\text { ¿Hay algún momento } \\
\text { en el que paren los } \\
\text { golpes? }\end{array}$ & $\begin{array}{l}\text { ho afesar de que te } \\
\text { lo aercetes muy } \\
\text { fuerte }\end{array}$ & $\begin{array}{l}\text { Porque esta circulando } \\
\text { la sangre g hohea } \\
\text { para }\end{array}$ \\
\hline $\begin{array}{l}\text { ¿A qué crees que } \\
\text { corresponde la } \\
\text { velocidad de los } \\
\text { golpes? }\end{array}$ & $\begin{array}{l}\text { " que esten cansado } \\
\text { o asestado }\end{array}$ & $\begin{array}{l}\text { Porque poede ser que } \\
\text { el corazón late fuerte } \\
\text { y el puso aumenta }\end{array}$ \\
\hline
\end{tabular}

Fuente: Datos de la investigación.

Al plantear estos cuestionamientos, se condujo a los estudiantes a estudiar el pulso desde una perspectiva métrica que guarda estrecha relación con la equipartición, pues las respuestas a las preguntas permiten concluir que percibieron una relación de igualdad de distancia entre una pulsación y la siguiente, mencionando además, que cumplen la condición de no parar en ningún momento y requerir de la acción de un fenómeno externo (correr, asustarse, cansarse...) para que ocurra un cambio en esa distancia. Además, quienes fueron más lejos afirmaron que, a pesar de que se presentara un cambio de velocidad por el cansancio, las pulsaciones conservarian la relación equidistante al momento de medirlas. 
Figura 6- Respuesta 1 categoría 2

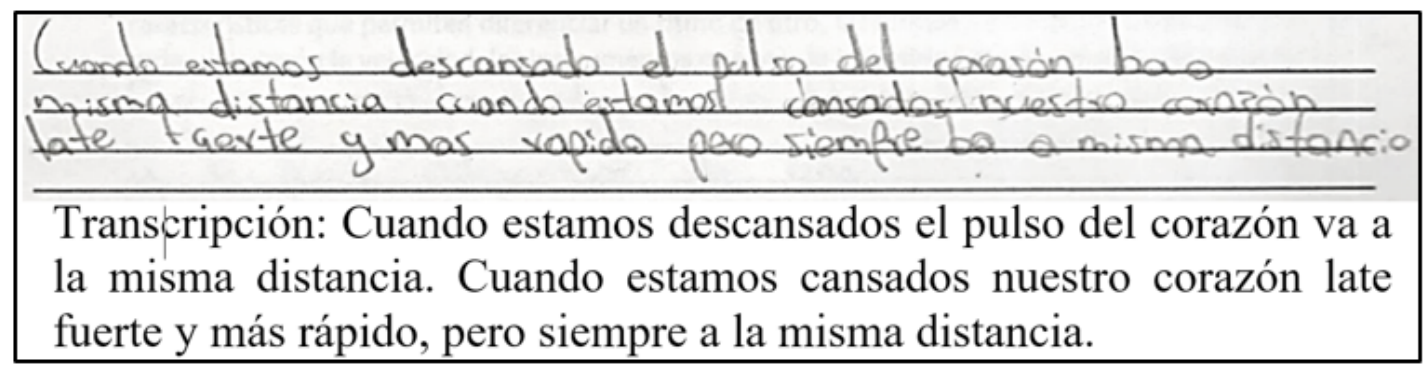

Fuente: Datos de la investigación.

Con esta actividad se estableció una aproximación a la noción de equipartición, sustentada en la percepción de medida en un campo continuo a través del análisis del tiempo transcurrido entre las pulsaciones y la continuidad de las mismas, dándole sentido infinito al pulso (Figura 6). Además, los cambios de velocidad que los estudiantes perciben con cada una de las actividades, en este caso en la relación cansado y asustado, apunta a una inicialización en la comprensión de la variación pues implica explicar cómo se relacionan las magnitudes variables en un problema particular, así como medir y analizar cómo cambian estas magnitudes. Los estudios sobre los fenómenos que cambian han sido una poderosa motivación del hombre para construir modelos matemáticos, los cuales se han representado con ecuaciones que relacionan variables (PARADA; CONDE; FIALLO, 2016).

Las conclusiones a las que llegaron los estudiantes poseen la condición de estar limitadas por sus formas de asimilación de la información y la estructuración de la misma en esquemas mentales. Además, a partir de ellas se pone en evidencia la diferencia entre el tiempo físico (medido por el reloj de manera estandarizada) y el tiempo percibido de forma subjetiva, en la mirada de Fraisse (1976) quien a través de sus estudios pudo establecer que la percepción que tienen las personas acerca del tiempo depende de las circunstancias en las que se da el procesamiento de la información recibida.

\section{Sistema de signos para medir el tiempo}

Con las respuestas de los estudiantes y los argumentos presentados en las secciones anteriores, se sentaron las bases para consolidar la construcción de la noción de equipartición. En esta etapa ya se cuenta con una forma de medir la duración de los sonidos y la comprensión de las cualidades de los mismos.

En la Tabla 2, presentamos una síntesis sobre las diferentes representaciones que fueron configurando la noción de equipartición por parte de los estudiantes. Dicha configuración se produjo desde dos maneras para estimar la duración del tiempo de un evento sonoro: i) haciendo uso de la idea de espacio recorrido en un tiempo determinado mediante situaciones en las que el estudiante establezca la relación entre la duración de tiempo y el espacio recorrido mediante trazas de longitudes (PIAGET, 1965); y ii) 
mediante experimentaciones de percepción auditiva de la pulsación del metrónomo, donde el estudiante experimente cambios entre pulsaciones lentas y rápidas sobre fenómenos sonoros.

Tabla 2- Sistema de signos para medir el tiempo

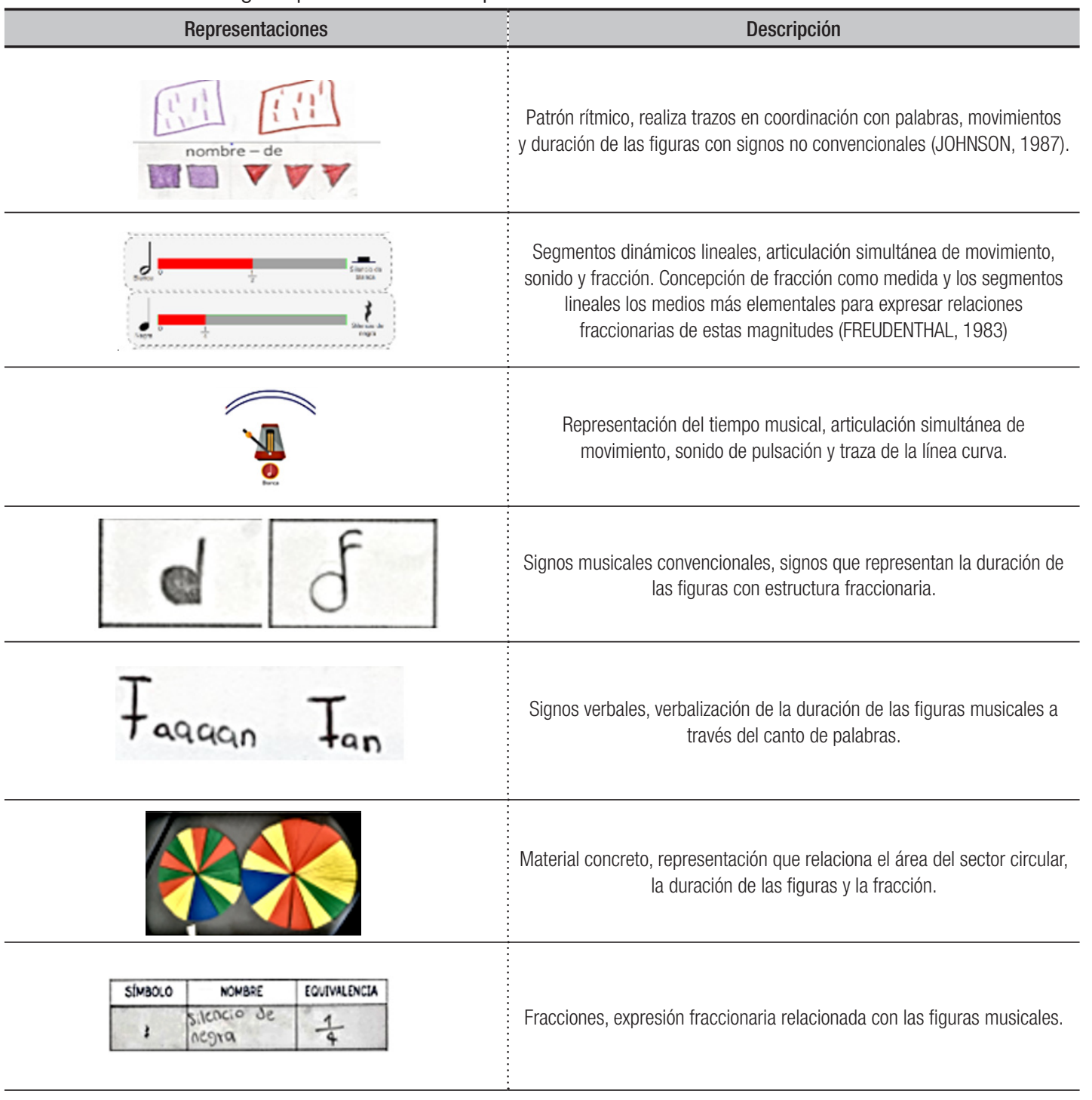

Fuente: Datos de la investigación.

En cualquier caso, el proceso de medir el tiempo de un evento sonoro exige la elección de una unidad, para expresar la duración de dicho evento en términos de esa unidad. 


\section{Toda figura de la misma clase tiene la misma duración}

Para iniciar, se retoma la estrategia de dibujo rítmico, en una actividad con la canción Pinto la cara del sol (MAYA, 2015). En esta tarea, los estudiantes desarrollaron ejercicios de comprobación, en los que en el caso de no terminar el dibujo a tiempo o hacerlo muy rápido, habría un estímulo auditivo, corporal y visual que les indicaría que se debe corregir algo en los movimientos. Aquí se enfatizó en la necesidad de conservar la igualdad en la duración de las figuras, relacionándolas con el tamaño del trazo que le corresponde y el carácter determinante de este principio para que el dibujo final fuese exacto, sustentando así la noción de equipartición.

En la búsqueda de observaciones, se les propuso a los estudiantes responder qué consecuencias encontraban al no manejar el mismo tamaño, trazo y tiempo dedicado a dibujar, en relación a la duración de cada figura musical. Algunas de las respuestas representativas de la mayoría de los estudiantes fueron:

\section{Figura 7- Respuestas 1 categoría 4}

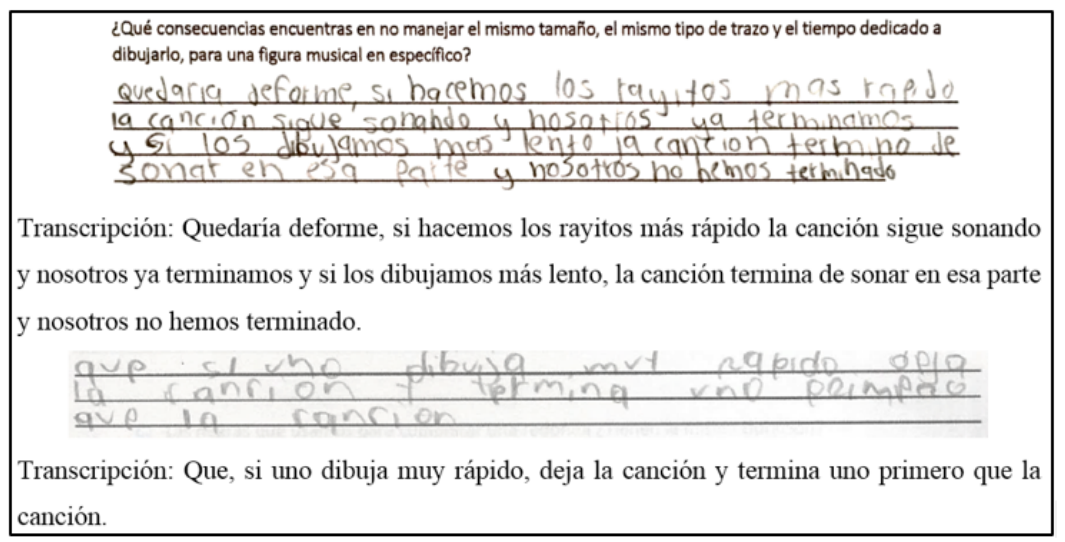

Fuente: Datos de la investigación.

Como se evidencia en la Figura 7, los estudiantes hicieron una relación acorde a las reglas de la métrica musical, marcando consecuencias observables de no seguir la equipartición con respecto al pulso y las diferentes figuras musicales que se vinculan con el dibujo y los sonidos. La alusión a la deformidad en la figura y terminar antes o después que la canción, son la muestra de una concepción implícita de necesidad de que todas las figuras de la misma clase respondan a la misma duración dentro de la canción.

Para ampliar esa propiedad, se propuso hacer uso de las herramientas virtuales, para mostrar varias animaciones. Se seleccionaron dos figuras, la negra y la corchea para recrear el evento en el que, de las cuatro negras que forman una redonda o las dos corcheas que forman una negra, una dura más o menos tiempo que las otras del mismo tipo. Para el caso, se reproducía un sonido correspondiente a una de las figuras, con una duración menor o mayor a los demás, a la vez de marcar un punto hasta donde llegaría el trazo si se prolonga ese sonido (ver Figura 8). 
Figura 8- Comparación de tiempos de duración entre figuras de la misma clase

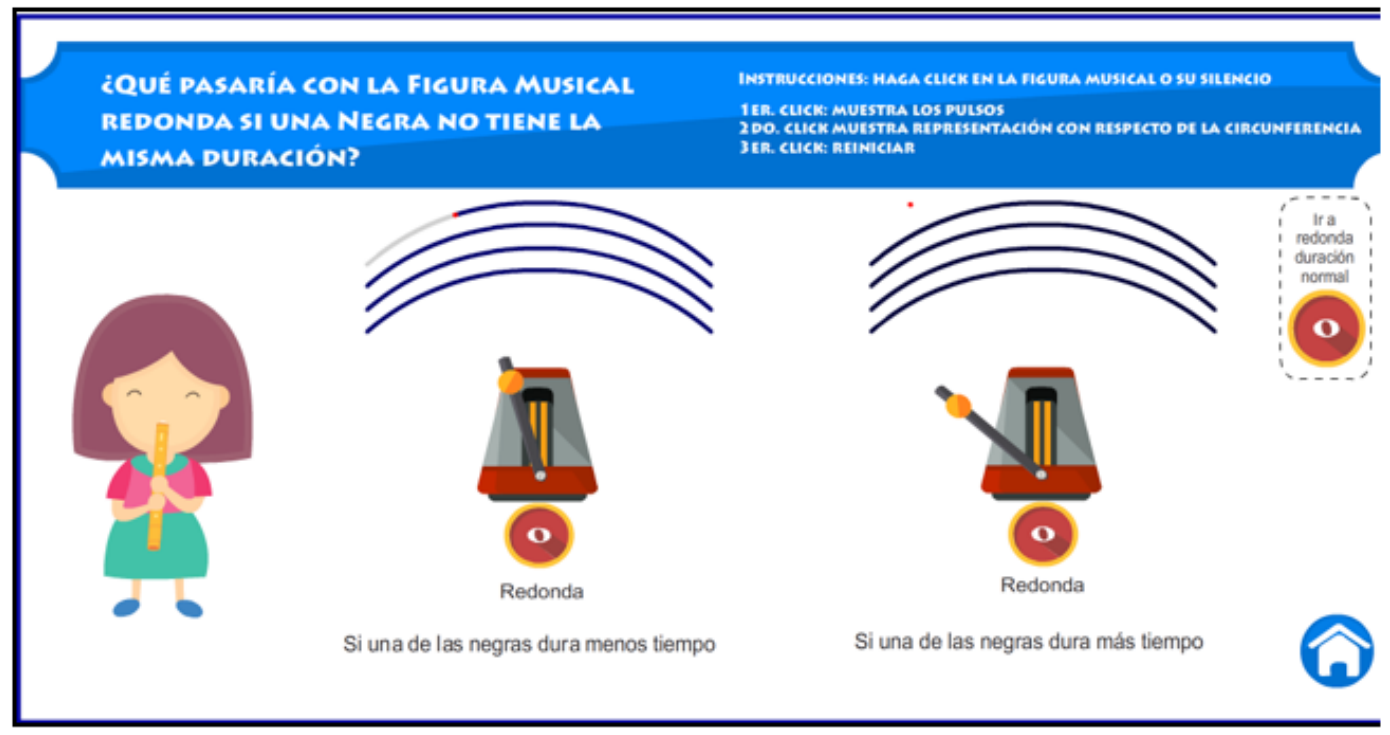

Fuente: Adaptación de multimedia (CONDE; PARADA; LIERN, 2016).

Las preguntas al respecto de los dos casos expuestos permitieron en los estudiantes la comprensión de una necesaria equidad de las partes dentro de las fracciones, puesto que se evidenció una consecuencia perceptible desde varias fuentes: el sonido duraba más o menos tiempo, una de las líneas era más larga o más corta; además, el sonido y los trazos acababan antes o después de marcar el golpe del pulso.

El siguiente diálogo entre el docente y los estudiantes permitirá conocer las impresiones generadas:

Docente: Vamos a ver qué pasa si una de las negras no tiene la misma duración (reproduce la animación).

Estudiante: Que el círculo no queda completo y le queda faltando un mochito (pedazo pequeño) para poder completar el pulso entero.

Docente: ¿para completar qué figura?

Estudiante: La figura redonda.

Docente: Entonces si estuviéramos interpretando una canción y todos los músicos tocaran la redonda completa, pero un músico la toca apenas hasta esta parte (señalando la figura presentada en la animación) ¿qué sucede?

Estudiante: Se pierde. (Episodio 1 - Fragmento de grabación de video de la clase).

El estudiante hizo una asociación de las formas establecidas previamente en las animaciones virtuales para la figura redonda, pensándola como un círculo formado por cuatro secciones correspondientes al tiempo que hay entre cada pulso, con el fenómeno de que uno de esos pulsos dure menos. Como se lee, el estudiante identificó que algo no 
estaba bien según las reglas y estableció una forma de describirlo -le falta un mochito-; pero no solo recurre a lo evidente para analizar el caso de tocar un instrumento, sino que también dota de sentido y contexto la ocurrencia del error, dejando claro que el músico que no sigue las reglas "se pierde".

Por otro lado, para la integración del material concreto con las situaciones virtuales y el análisis matemático, recurrimos a la representación de casos en los que la equipartición no se cumple, recreando la pregunta ¿qué pasa si una de las negras que componen una redonda, dura más o menos tiempo?

En una de las videograbaciones se registra la siguiente respuesta:

\footnotetext{
Estudiante: Le voy a leer la pregunta (inicia a leer) sabemos que en una redonda caben cuatro negras, pero ¿Qué pasaría si una de las negras tuviera menor duración que las demás? (retoma la explicación) por ejemplo, en la canción que cantamos ahorita [Pinto la cara del sol] era con... ¿con cuál era?

Docente: Con la blanca.

Estudiante: Con la blanca, entonces así (muestra en la hoja de trabajo y dibuja) cuando estábamos haciendo los ojos era como (canta) taan taan, entonces si era con otra, como con una negra, quedaría (inicia dibujo del primer ojo) taan y entonces aquí (inicia dibujo del segundo ojo) ta, quedaría un ojo mocho, quedaría en la mitad.

Docente: ¿Entonces es posible que dentro de la redonda digamos que la vamos a llenar con cuatro negras, pero que una de esas sea de diferente duración?

Estudiante: No. (Episodio 2 - Fragmento de grabación de video de la clase).
}

Esta explicación permite evidenciar la idea que el estudiante ha construido de la equipartición. Usa las herramientas físicas y simbólicas para argumentar y comprobar sus conjeturas sobre la construcción o no de partes iguales de una unidad. Según Conde, Parada y Liern (2016), existe una consecuencia acústica percibida por los estudiantes que les permite dar un significado a las equiparticiones, realidad que no posee en el ejemplo tradicional del pastel.

\section{El compás como composición de equiparticiones}

Aquí se concibe el compás como una división del tiempo musical en partes iguales de duración y se representa con una fracción que le indica al músico cuántos pulsos tendrá cada compás.

Para introducir a los estudiantes en el estudio de este objeto musical, se realizaron actividades de baile en diferentes ritmos, algunos fueron ejemplificados por ellos mismos y otros fue necesario mostrarlos en video. Adicionalmente, a partir de la multimedia se presentó la estructura musical de los patrones rítmicos del vals y el reggaetón, explicando la lógica de construcción de los compases y su relación con la forma de bailarlos. 
Figura 9- Patrón rítmico del vals

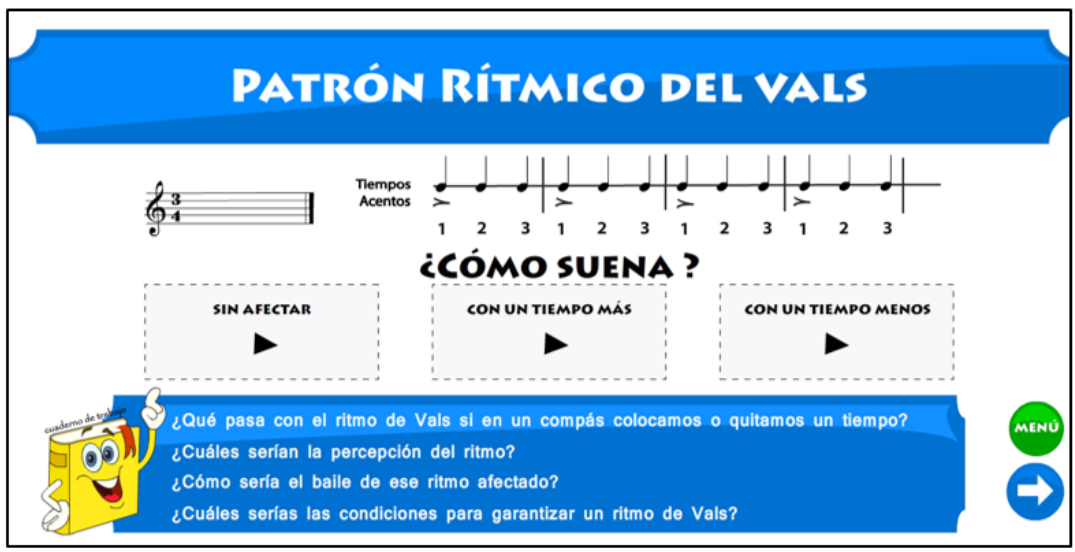

Fuente: Multimedia de la investigación (registro: 13-67-227). Acceso público.

En la Figura 9 se plantea un patrón rítmico donde se altera uno de los compases (tiempo de duración) y se espera descubrir el compás alterado y sus consecuencias acústicas. Algunas de las respuestas recibidas fueron:

Figura 10- Respuestas 1 categoría 5

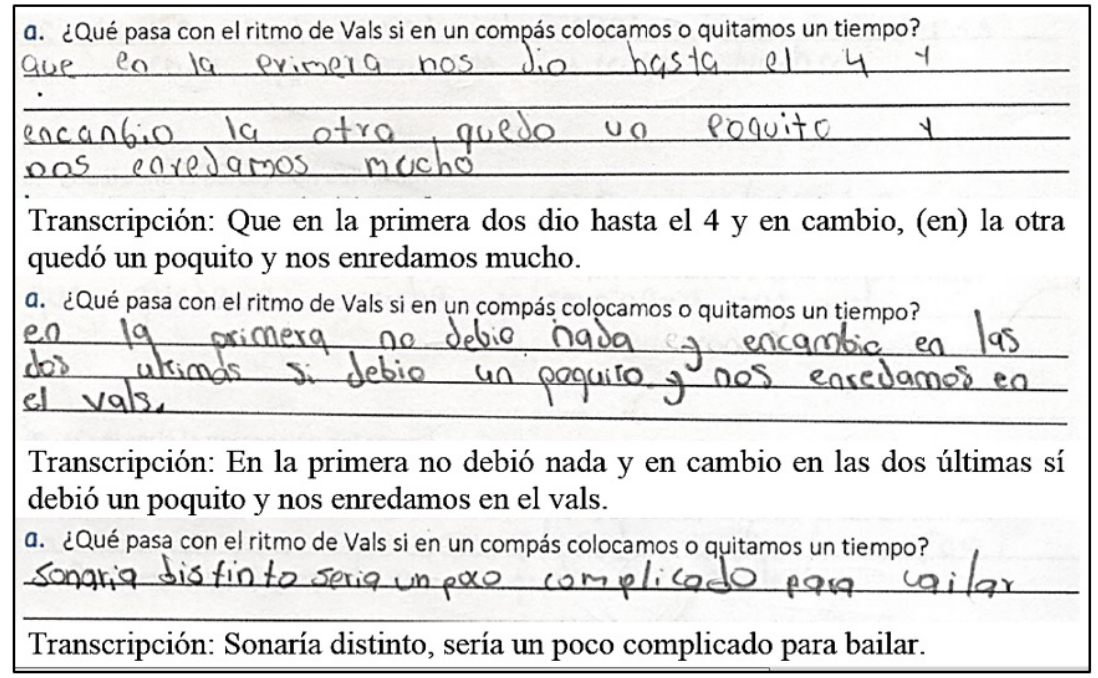

Fuente: Datos de la investigación.

En las dos primeras respuestas de la Figura 10, los estudiantes apoyan sus explicaciones sobre el no cumplimiento de la equipartición en representaciones corporales, refiriéndose a los pasos de baile. Mientras que la tercera respuesta hace uso de representaciones auditivas que luego son relacionadas con representaciones corporales. 
Para el inciso b, (Figura 11) la pregunta explora las percepciones de los estudiantes sobre el patrón rítmico propuesto en la Figura 9. Al respecto los estudiantes responden:

Figura 11- Respuestas 2 cateqoría 5

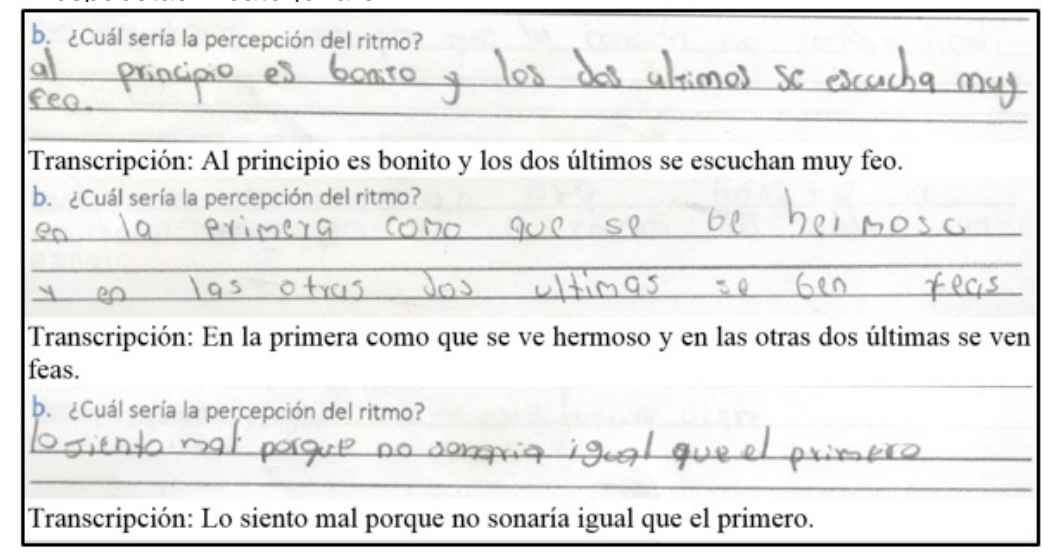

Fuente: Datos de la investigación.

Las apreciaciones de los estudiantes tienden a la dimensión estética, de mantener el orden, de cumplimiento de una regla, que de una u otra forma valora lo percibido a través de los oídos. Las conexiones entre la belleza, la medida y la exactitud son manifestaciones de los estudiantes sobre la equipartición entre los compases del patrón rítmico.

En la Figura 12, se observa que los estudiantes hicieron uso de los conocimientos adquiridos para evaluar algunas composiciones en busca de errores en los compases según las reglas músico-matemáticas, apoyados en el material concreto.

Figura 12- Respuestas 3 categoría 5

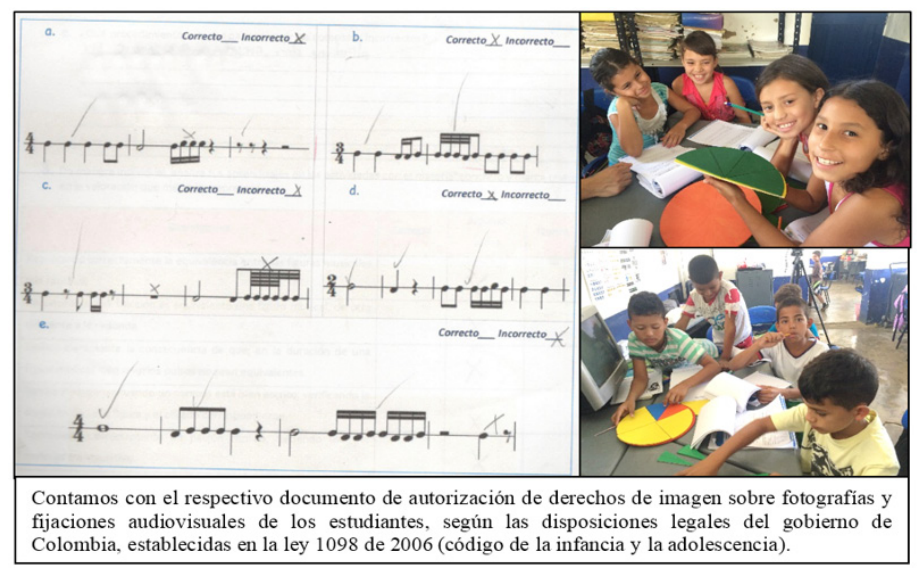

Fuente: Datos de la investigación. 
La forma de analizar cada linea musical se describe con la siguiente explicación dada para el literal c:

\begin{abstract}
Estudiante 1: Aquí comprobamos que esta está mala porque aquí pusimos todas las que eran (señala el material manipulativo) y acá sobraba una, entonces no cabía la negra.

Estudiante 2: 0 sea que viene sobrando esta semicorchea (muestra la ficha levantándola con la mano), porque si quitamos esta semicorchea, ahora sí cabe la negra entera. Vea, entonces (quita la semicorchea que indicó que estaba sobrando) así quedaría un compás de tres cuartos, pero como viene hasta acá (pone la ficha de nuevo y muestra el exceso), no quedaría un compás de tres cuartos porque no cabe la negra entera. (Episodio 3 - Fragmento de grabación de video de la clase).
\end{abstract}

Como se evidencia, hubo una correcta interpretación de la dinámica de evaluación de los compases y las características que permitían concluir la existencia o no de un error, aun cuando la complejidad del ejercicio discutido representó grandes dificultades.

\title{
Conclusiones
}

Los estudiantes establecen relaciones entre las matemáticas y la música, otorgando sentido matemático a las preconcepciones que poseen acerca de la identificación de los sonidos. Hacen evidentes sus cualidades y diferencias entre sí. En esta etapa descubren la existencia de una cualidad preponderante para el objetivo perseguido: la duración, como elemento susceptible de ser medido. Esta comprensión inicial es intuitiva, pues no poseen un sistema de comprobación de la exactitud del tiempo de duración de un sonido. Lo anterior son bases fundamentales como inicio del proceso y dar cuenta de la pregunta de investigación: ¿Cómo construyen los estudiantes de primaria la noción de equipartición, a través de objetos musicales?

Los estudiantes descubren, estudian y comprenden la forma como el pulso, el tiempo y el ritmo musical constituyen una aproximación a la noción de equipartición, a la par de darle al pulso la condición de ser la unidad de medida de la música. Aquí se observa la equipartición en la condición de que la distancia entre cada pulso, sin importar el tiempo musical y patrón rítmico de una canción, debe ser la misma.

Acto seguido, los estudiantes encuentran que hay una forma de establecer unidades de medida a partir del pulso, que pueden ser convencionales o no convencionales inicialmente, hasta cobrar forma en las figuras musicales como lenguaje universal para expresar la duración de un elemento sonoro de la música. Además, establecen una relación fraccionaria entre cada una de ellas, partiendo de la redonda como unidad y las demás como cierta parte de ella, siguiendo la propiedad de que cada figura es la mitad de la anterior y el doble de la siguiente.

Gracias a este descubrimiento, aprehenden que en este lenguaje se cumple una propiedad inquebrantable: todas las figuras de la misma clase tienen la misma duración. Esta propiedad es evaluada en condiciones de incumplimiento de la regla, alterando la duración de una de las figuras que podría ser equivalente a la otra. La comprobación 
de dicha regla se hizo a través de representaciones dinámicas computacionales, uso de material concreto y representaciones corporales, en la tarea de establecer una consecuencia perceptible en el fenómeno descrito.

En este nivel ya poseen las bases y concepciones necesarias para la construcción de la noción de equipartición. Éstas dependen de las representaciones externas para construir representaciones internas correspondientes al objeto en estudio, la equipartición. Al mismo tiempo, las diferentes representaciones semióticas y argumentaciones expresadas por los estudiantes serán los insumos que le permitirán al docente hacer una valoración sobre la construcción de la noción.

Finalmente, los estudiantes se involucran en la tarea de concebir el compás como un conjunto de equiparticiones, evaluando la correcta composición de líneas musicales, explorando la partición presente en pasos de baile y analizando la alteración de patrones rítmicos. En todos los casos, se busca reafirmar que no sería posible escribir, interpretar o bailar una composición musical sin seguir las reglas de equipartición. Es en este proceso donde los estudiantes construyen la noción de equipartición mediada por las formas diferentes de representación, la comprobación por sus propias prácticas y socialización de las mismas con los demás.

Como reflexión final, se sugieren cambios en la escuela tradicional en cuanto a herramientas y argumentos para el estudio de las fracciones. Una insinuación podría ser reorientar los procesos de enseñanza y aprendizaje de la equipartición, a través de objetos musicales. Aquí se generan diversos escenarios didácticos que pueden favorecer el aprendizaje de las fracciones con base en su estructura métrica musical.

\section{Referencias}

ARCAVI, Abraham. The role of visual representations in the teaching and learning of mathematics. In: HITT, Fernando; SANTOS, Manuel (Eds.). ANNUAL MEETING OF PME-NA, 21., 1999, Ohio. Proceedings of... Ohio: Clearinghouse for Science, Mathematics, and Environmental Education Columbus, 1999. p. 55-80.

ARZARELLO, Ferdinando et al. Gestures as semiotic resources in the mathematics classroom. Educational Studies in Mathematics, Netherlands, v. 70, n. 2, p. 97-109, 2009.

CONDE, Alexander. La unidad relativa como vínculo cognitivo entre el tiempo musical y las fracciones. México D.F.: IPN, 2013. 192 p. Tesis (Doctorado en Matemática Educativa) - Centro de Investigación y Estudios Avanzados del Instituto Politécnico Nacional, México DF, 2013.

CONDE, Alexander. Las fracciones al ritmo de la música. 2009. 215 p. Tesina (Maestría en Ciencias especialidad Matemática Educativa) - Centro de Investigación y Estudios Avanzados del Instituto Politécnico Nacional, México, DF, 2009.

CONDE, Alexander; PARADA, Sandra; LIERN, Vicente. Estudio de fracciones en contextos sonoros. Revista Actualidades Investigativas en Educación, San Pedro de Montes de Occa, v. 16, n, 2, p. 1-21, 2016. 
CORTINA, José; ZÚÑIGA, Claudia; VISNOVSKA, Jana. La equipartición como obstáculo didáctico en la enseñanza de las fracciones. Revista Educación Matemática, México, DF, v. 25, n. 2, p. 7-29, 2013.

D’AMORE, Bruno. Conceptualización, registros de representaciones semióticas y noética: interacciones constructivistas en el aprendizaje de los conceptos matemáticos e hipótesis sobre algunos factores que inhiben la devolución. Revista Científica, Bogotá, v. 11, p. 150-164, 2009.

DE GUZMÁN, Miguel. El rincón de la Pizarra. Madrid: Pirámide, 1996.

DUVAL, Raymond. Registros de representación semiótica y funcionamiento cognitivo del pensamiento. In: HITT, Fernando (Ed.). Investigaciones en matemática educativa II. México, DF: [s. n.], 1998. p. 173-201.

FENLON, lain. La música y el tiempo. In: LIPPINCOTT, Kristen (Ed.). El tiempo a través del tiempo. Barcelona: Grijalbo Mondadori, 2000. p. 214-219.

FRAISSE, Paul. Psicología del ritmo. Madrid: Morata, 1976.

FREUDENTHAL, Hans. Fenomenología didáctica de las estructuras matemáticas. México, DF: Departamento de Matemática Educativa del Cinvestav-IPN, 1983.

GODINO, Juan et al. Didáctica de las Matemáticas para maestros. Granada: Universidad de Granada, 2004. JOHNSON, Mark. The body in the mind. Chicago: University of Chicago Press, 1987.

KIEREN, Thomas. On the mathematical, cognitive, and instructional foundations of rational numbers. In: LESCH, Richard (Ed.). Number and measurement. Ohio: ERIC/SMEAC, 1976. p. 101-149.

KIEREN, Thomas. Personal knowledge of rational numbers: Its intuitive and formal development. In: HIEBERT, James; BEHR, Merlyn (Ed.). Number concepts and operations in the middle grades. Reston: National Council of Teachers of Mathematics, 1988. p. 162- 181.

KIEREN, Thomas. The racional number constructs. Its elements and mechanisms. In: KIEREN, Thomas (Ed.). Recent research on number learning. Columbus: ERIC/SMEAC, 1980. p. 128-149.

LIERN, Vicente. Música y matemáticas en la educación primaria. Revista Suma, Catalunya, v. 66, p. 107-112, 2011.

MAYA, Tita. Dibujo rítmico trazos y garabateo. Medellín: Corporación Cantoalegre, 2015.

McADAMS, Stephen. Recognition of sound sources and events. In: McADAMS, Stephen; BIGAND, Emmanuel (Ed.). Thinking in sound: the cognitive psychology of human audition. Oxford: Oxford University Press, 1993. p. 146-198.

NAIK, Shweta; SUBRAMANIAM, K. Integrating the measure and quotient interpretation of fractions. In: CONFERENCE OF THE INTERNATIONAL GROUP FOR THE PSYCHOLOGY OF MATHEMATICS EDUCATION, 32., 2008, Morelia. Proceedings of the... PME 32 and PME-NA XXX, v. 4. Morelia: [s. n.], 2008. p. 17-24. 
PARADA, Sandra; CONDE, Alexander; FIALLO, Jorge. Mediación digital e interdisciplinariedad: una aproximación al estudio de la variación. Bolema, São Paulo, v. 30, n. 56, p. 1031-1051, 2016.

PERALTA, Javier. Matemáticas para no desafinar. Gaceta de la Real Sociedad Matemática Española, Madrid, v. 6, n. 2. p. 437-456, 2003.

PÉREZ, Manuel. Una pedagogía dialógica desde la educación artística-musical. El Artista, Pamplona, v. 6, p. 60-72, 2009.

PIAGET, Jean. El desarrollo de la noción de tiempo en el niño. México, DF: Fondo de Cultura Económica, 1978.

PIAGET, Jean. La construcción de lo real en el niño. Buenos Aires: Proteo, 1965.

PREDIGER, Susanne; SCHINK, Andrea. "Three eighths of which whole?" - Dealing with changing referent wholes as a key to the part-of-part-model for the multiplication of fractions. In: TZEKAKI, Marianna; KALDRIMIDOU, María; SAKONIDIS, Haralambos (Ed.). CONFERENCE OF THE INTERNATIONAL GROUP FOR THE PSYCHOLOGY OF MATHEMATICS EDUCATION, 33., 2009, Thessaloniki. Proceedings of the... PME. v. 1. Thessaloniki: [s. n.], 2009. p. 409-416.

SCHAEFFER, Pierre. Tratado de los objetos musicales. Madrid: Alianza, 1988.

SHILLING, Wynne. Mathematics, music and movement: Exploring concepts and connections. Early Childhood Education Journal, Netherlands, v. 29, n. 3, p. 179-184, 2002.

SILVA, Eddie. Música como estrategia educativa en el proceso enseñanza aprendizaje para el aprovechamiento académico de los estudiantes a nivel elemental en la región educativa de Bayamón. 2009. 127 p. Tesina (Maestría en Administración y Supervisión Educativa) - Universidad Metropolitana, Río Piedras, 2009.

SOCAS, Martín. Dificultades, obstáculos y errores en el aprendizaje de las matemáticas en la educación secundaria. In: RICO, Luis (Ed.). La Educación matemática en la enseñanza secundaria. Barcelona: Horsori, 1997. p. 125-154.

TIBURCI0, Susana. Música y matemáticas. Elementos, Puebla, v. 44, n. 8, p. 21-26, 2002.

VYGOTSKY, Lev. Pensamiento y lenguaje. Barcelona: Paidós, 1995.

WILENSKY, Uri. Abstract meditations on the concrete, and concrete implications for mathematics education. In: HAREL, Idit; PAPERT, Seymour (Ed.). Constructionism. Norwood: Ablex, 1991. p.193-204.

ZBIKOWSKI, Lawrence. Conceptual models and cross-domain mapping: new perspectives on theories of music and hierarchy. Journal of Music Theory, New Haven, v. 41, n. 2, p. 193-225, 1997. 
Gerardo Elías Sepúlveda Restrepo es magíster en Educación Matemática (Universidad de Medellín). Docente tutor, Programa para la Excelencia Docente - Todos a Aprender (PTA), Secretaría de Educación de Antioquia, Colombia.

Marco Antonio Ayala Chauvin es magíster en Educación Matemática (Universidad de Medellín). Docente investigador de la Universidad Técnica Particular de Loja, Ecuador.

Luis Alexander Conde Solano es doctor en Matemática Educativa (CINVESTAV-IPN, México). Profesor-Investigador y líder del Grupo de Investigación SUMMA de la Facultad de Ciencias Básicas de la Universidad de Medellín, Colombia. 